\title{
Comparative Study of Physics Curriculum in Iran with Several Other Countries
}

\author{
Ashrafoalsadat Shekarbaghani ${ }^{1}$ \\ ${ }^{1}$ Education Studies Research Center, Organization for Educational Research and Planning (OERP), Tehran, Iran \\ Correspondence: Ashrafoalsadat Shekarbaghani, Education Studies Research Center, Organization for \\ Educational Research and Planning (OERP), Tehran, Iran. E-mail: a20.baghani@gmail.com
}

Received: January 13, 2016

Accepted: February 23, $2016 \quad$ Online Published: July 26, 2016

doi:10.5539/ies.v9n8p112

URL: http://dx.doi.org/10.5539/ies.v9n8p112

\begin{abstract}
This article is a qualitative study, which was done in 2013-2014. In this study using a comparative study was conducted to compare physics curriculum elements of Iran with the countries studied. Countries studied: Singapore, Turkey, India, England and Australia have diverse educational system. In this study, the structure of the educational system, the physics curriculum, teaching methods, students' achievement evaluation methods were studied and compared. The aim of the research was to identify the Features of the physics curriculum in Iran. In some cases, similarities and differences were observed. From the major problems in the physics curriculum of Iran is many number of books is more than in other countries. And time teaching physics Iranian schools is less than in other countries, While the content of physics books of Iranian schools from all countries studied is further and to do physics experiments in Iranian schools are of less importance. Iran evaluation system is the traditional way and held for final evaluation. The results can help to educational planners and authors of physics textbooks for perform more accurate and more comprehensive correction to the physics curriculum.
\end{abstract}

Keywords: Australia, comparative study, England, Iran, India, physics curriculum, Singapore, Turkey

\section{Introduction}

\subsection{Introduce the Problem}

Due to a change in approach to science education at the global level, the issue of updating the content of physics textbooks which could affect students with the knowledge, attitudes and skills, to better coordinate them with the current life changes, more than anything else, that is interest to authors and experts of producing physics textbook have been. Thus, the process of curriculum development appears more and more important and the role of curriculum planning seems more important. An effective physics curriculum, in fact, is a curriculum based on problem-solving process (The research and educational programs department, 2001, p. 16). In program design, learner ability to learn and active methods of learning are emphasized, also how to learn and development of thinking skills has been focused instead of providing and maintaining the content. Since sciences and technology development, has changed the world around us in general, so the knowledge of this development, especially in the area of curriculum and knowing the right way to use them on the one hand and providing a background to flourish of genius, creativity and talents on the other hand caused us to identify true needs and interests of students, a good curriculum is designed and make (Maleki, 2001, p. 43).

Therefore it is necessary to study comparative assessment of leading countries in education and curriculum development to achieve effective, continuous improvement and updating of textbooks. Many education experts believe that one of the major inhibiting factors, that prevent significant changes in education system, is restrictions of old and unscientific traditions on the provision of education, assessment and evaluation (Shabani, 2006 , p. 27). Therefore, it is necessary to study the curriculum of leading countries in education to move over these obstacles.

\subsection{Explore Importance of the Problem}

The studies shown that in spite of several change in the field of content and training procedures of physics curriculum in recent years, it seems there is long distance to achieve education goals and the current changes could not meet the high order goals. Level of scientific literacy of school graduates in physics and maintaining time of the learned material is very low and in spite of procedure change of laboratory and incorporating it to the 
content of the lesson, the intangible change in feedback against education system has not yet seen (Fathi-Vajargah, 2002, p. 121). Thus it is necessary to do a comparative study and identify program weaknesses and physics textbooks.

On the other hand studies have shown that in development of physics textbooks, to make close relation between the scientific level and content of textbooks to textbooks of developed countries, it should be noted some points including (Khalkhali, 1996, p. 87):

1) Due to the educational grade level of programs and distribute them in the four years of high school and pre-university degree.

2) Attention to the intellectual and emotional growth of Iranian and foreign students.

3) Attention to the content distribution of age groups and observing the abstraction abilities of students.

It has to demonstrate a specific concept can be raised on what level and grade. Education grade, time positions in a grade, scope and depth of concepts are of particular importance in the curriculum. It should be clearly understood that a specific approach in what grade and which year is considered. What did students learned about these concepts? Which secondary concept of this general concept has been discussed at the same level (Fathi-Vajargah., 2002, p. 125)?

Thus the basic prerequisite of making the necessary changes in the curricula of physics is to study the physics curriculum in other countries that pursue an active approach, in order to use the research findings and review the current programs, to resolve the problems of the physics curriculum in high school and pre-university and try to offer the best solution to it.

\section{Method}

Given the nature of research in this study (descriptive- applied), qualitative analysis will be used to analyze the data. This study has been done in a qualitative survey method because the required data are classified in separate classes using the current documents about the studied countries in order to analyzed and compared. This study used Beredy pattern. He believes that a comparative study is impossible without any clear procedure. He identified four steps in the comparative study of education:

1) Description, 2) interpretation, 3) neighborhood, 4) comparison.

After collecting documents and describe them, we can examine, interpret the neighborhood and compare this information. This stage will be conducted using statistical methods relating to qualitative research (Shekarbaghani, 2009, p. 65).

\subsection{Research Design}

Case study is done about physics curriculum in England, Australia, Singapore, Turkey and India, which compares with Iran. Each education systems of these countries have been chosen because of some reasons such as having an important role in defining international Education standards, innovation in favorable ways to curriculum, existence of similar problems and obstacles; the study is to answer the following questions:

1) Are the teaching method of physics different in different countries?

2) Are the quality of evaluation and types different in different countries?

3) How is the training time of basic physics concepts in consecutive periods and grades in different countries?

4) How are laboratory, practical and project learning in various countries look like?

5) Is there same content organization in programs and textbooks in different countries?

6) What is the common content of physics textbooks between Iran and the studied countries regard to cognitive areas?

7) What is the difference in content of physics textbooks between Iran and the studied countries regard to cognitive areas?

\section{Results}

Question 1: Are the teaching method of physics different in different countries?

Teaching methods of the studied countries are shown in Table 1. 
Table 1. Comparison of teaching methods in the studied countries with Iran

Physics curriculum

Countries

studied

Special methods for improving the education needs of different students, participation of students in learning, such as learning based on research, exploratory and experiential learning that enables deeper understanding of learning concept to students( Winston, 2007:62).

In addition to the transfer of knowledge, the improvement of skills and attitudes has paid special attention, so different tasks and activities have been in textbooks to strengthening and achieve these objectives. Learning is enhanced using the skills, understanding and responsibility based on the concepts of life (Turkish Ministry of National Education, 2007, p. 94-100).

Along with emphasizing new approaches, it is focused to diagnose the importance of structure, traditions, customs, traditions and values ruling the community and different races in country as an active exploration approach. (The Central Board of Secondary Education, 2011, p. 65).

They use problem solving skills and shared the theoretical concepts, which they are taught to each other. They embrace contribution to increase the students understanding of the world live in it. Generally, teaching methods encourage students to understand the concepts and knowledge in the certain field and this creates an independent, creative, responsible, confident and prepared learner to find his place in society (The Board of studies, 2004: 21\&41).

Physics teaching methods in England schools have been done using heuristic methods, laboratory and demonstration, playing role and new quite active approaches for delivering the course content, usually teacher's role is to guide and act as a consultant in classroom (AQA, 2008, p. 125).

However, the curriculum insists on active method, but in most schools, the traditional method commonly speech is used to deliver content. Classes are usually controlled in the form of teacher-centered. In fact, the teachers have not knowledge about basic assumptions of new Singapore procedures of Science (The research and educational programs department, 2001).

Question 2: Are the quality of evaluation and types different in different countries?

Evaluation of the quality and variety of the studied countries are shown in Table 2.

Table 2. Comparison of evaluation methods in the studied countries with Iran

Evaluation methods

Countries

studied

Every year students through assignments, projects, content test and performance as well as practical and laboratory activities evaluated by their teacher. Teacher prefer the extensive utilization of alternative evaluation models to prepare students in order to solve difficult problems that they might face in the future. To understand whether students have learned the issues or not, it should be evaluated using evaluation test in general and in detail, Since 2006, graduated high school and pre-university exams in all disciplines will be held through standardized and international GCE tests(the Ministry of Education Singapore, 2007, pp. 10-11).

Test questions are designed by the evaluation department in accordance with the exact analysis of content. Each question is discussed in Preparation process even in detail to determine the student progress which is measured using questions. The questions include not only multiple choice questions, but also explanatory questions. Statistical analysis on any question has done with the precise details at this stage, so the questions which seems difficult, are not mentioned in the main exam. As a result, after determination of the technical specifications of questions, the question quality will be increases. When the exam questions are prepared on this basis, along with questions that students can answer them using their memory, as well as meta knowledge questions are offered (Turkish Ministry of National Education, 2007, pp. 113-115). 
Schools are responsible for carrying out tests of high school in the ninth and eleventh grades, but the state secondary teaching board is responsible of the evaluation in the tenth and twelve grade whose done by holding various standardized tests in cooperation with the qualified teachers. In addition to the practical exam, the theoretical test is considered for physics book. As the following table is used for the practical test: a test of a custom part: 7 score, the activity of two parts (a total of two activities): $3.5+3.5=7$ score, writing a research project and an oral exam based on it: 5 scores, practical record of experiments and activities (work report): 6 score, an oral exam based on experiments and activities: 5 score. The total score of the practical exam: 30 score, total score of the theory exam: 70 score (The Central Board of Secondary Education, 2011, p. 70).

Australia's states and territories enjoy their own evaluation system. Thus in high school level, the highest score or rank is displayed by using the Latin letter A, the lowest score or rank with Latin letter E. For the evaluation of physics, experimental work as well as empirical is important. Experimental work includes an open research in the field of knowledge and Perception of skills achievements in both preliminary and advanced parts. Practical experience should be emphasized that the activities in process which includes laboratory experiments, the use of specific computer based on digital technology, undertaking laboratory experiments, reorganize the data in tables, graphs and so on (The Board of studies, 2004, pp. 80-81).

Teacher has held a variety of evaluation and continuous tests to have sufficient knowledge of the student, to evaluate the level of his development. The evaluation has a great value for the selection of routes to universities and for employers. The transition from one stage to the next is required to hold the entrance national tests in schools. The evaluation of students 14-19 years applied by educational circles outside schools. At the end of the preliminary stage of secondary education (age 16 years) the course certificate will be offered to students. This examination can investigate the ability of students in the special and separate education subjects based on the scale selection (A-G). It should be said that the grades (A-C) indicate that the students passed the course. Advanced level of knowledge is hold 2-4 tests (AQA, 2008, p. 5, 8).

Iran evaluation system is the traditional way and held for final evaluation. Evaluation of the third year of high school physics that led to the diploma will be held by entrance examination, but this entrance examination makes worry and psychological problems for the students (Shekrbaghani, 2006, p. 43).

Question 3: How is the training time of basic physics concepts in consecutive periods and grades in different countries?

Question 4: How is laboratory, practical and project learning in various countries look like?

Answers to questions 3 and 4, that is training time in consecutive periods and grades and experimental, practical and project learning in the studied countries are shown in Table 3. 
Table 3. Comparison of physics textbooks in studied countries (in terms of physics in grades, the timetable, the optional subjects, of being student-centered, teaching with experiments)

\begin{tabular}{|c|c|c|c|c|c|c|}
\hline $\begin{array}{c}\text { Teaching with } \\
\text { experiments }\end{array}$ & Student-centered & $\begin{array}{l}\text { Optional } \\
\text { subjects }\end{array}$ & Timetable & \multicolumn{2}{|c|}{ Physics in grades } & $\begin{array}{c}\text { Countries } \\
\text { studied }\end{array}$ \\
\hline high & $15 \%$ of Hours & No & 144 & \multicolumn{2}{|c|}{ Third grade } & Sincono \\
\hline high & $15 \%$ of Hours & Yes & 144 & \multicolumn{2}{|c|}{ Fourth grade } & Singapore \\
\hline high & High & No & 72 & \multicolumn{2}{|c|}{ Nine grade } & \\
\hline high & high & No & 72 & \multicolumn{2}{|c|}{ Tenth grade } & Turlar \\
\hline high & high & No & 108 & \multicolumn{2}{|c|}{ Eleven grade } & 1 UIкеу \\
\hline high & high & No & 108 & \multicolumn{2}{|c|}{ Twelve grade } & \\
\hline $30 \%$ & high & No & 360 & \multicolumn{2}{|c|}{ Eleven grade } & India \\
\hline $30 \%$ & high & No & 360 & \multicolumn{2}{|c|}{ Twelve grade } & mura \\
\hline $30 \%$ & high & high & No & \multicolumn{2}{|c|}{ sixth grade preliminary } & Australia \\
\hline $30 \%$ & high & high & 120 & \multicolumn{2}{|c|}{ Advanced } & \\
\hline high & high & No & 108 & \multicolumn{2}{|c|}{ Tenth grade } & \\
\hline high & high & No & 108 & \multicolumn{2}{|c|}{ Eleven grade } & England \\
\hline high & high & No & 108 & \multicolumn{2}{|c|}{ Twelve grade } & \\
\hline Low & Low & No & 108 & \multicolumn{2}{|c|}{$\begin{array}{l}\text { The first year of } \\
\text { secondary }\end{array}$} & \\
\hline Low & Low & No & 108 & \multicolumn{2}{|c|}{$\begin{array}{c}\text { The second year of } \\
\text { secondary }\end{array}$} & \\
\hline Low & Low & No & No & $\begin{array}{l}\text { Natural } \\
\text { science }\end{array}$ & $\begin{array}{l}\text { The third } \\
\text { year of }\end{array}$ & \\
\hline Low & Low & No & No & Math & secondary & Iran \\
\hline No & No & No & No & \multicolumn{2}{|l|}{ Physics1(N) } & \\
\hline No & No & No & No & \multirow{3}{*}{$\begin{array}{l}\text { Physics1(M) } \\
\text { Physics2(N) } \\
\text { Physics2(M) }\end{array}$} & & \\
\hline No & No & No & No & & $\begin{array}{c}\text { Pre } \\
\text { university }\end{array}$ & \\
\hline No & No & No & No & & & \\
\hline
\end{tabular}

Note. "N" indicates Natural science and "M" indicates Math in Table 3.

According to Table 3, the numbers of physics books in Iran are more than other studied countries and the extent of contents is not fitted to the timetable, so the discussions must be reduced in regard to the considered time to achieve an appropriate level.

Question 5: Is there same content organization in programs and textbooks in different countries?

Similarities: Comparison of physics textbooks between Iran and the studied countries shows the active presentation method is focused in all countries curriculum . These countries have same purpose of physics training. The organization is provided in certain order and specific discussions, there are new and updated discussions in these books which creates them attractive to students.

Differences: Comparison of physics textbooks between Iran and the studied countries shows that physics book works in almost all countries except Iran as student-centered method. In all these countries the teaching of physics will be presented by using experiments. Teachers are forced to state all details because of lack of experiments, so this waste more class time, while in the studied countries, the teaching process will be done with experiment, so the students learn faster and have more experience skills than Iranian students.

In Iran, more grades are taught physics but the studies countries initiated the physics teaching in fewer grades but the older students, so that in Singapore, India and Australia, the physics teaching is provided in two grades for 
students 17-18 years old. In England, the physics teaching is provided in three grade for students $16,17,18$ years old and in Turkey as well as Iran, training is planned in four grade for students 15 years and then 16, 17 and 18 .

Question 6: What is the common content of physics textbooks between Iran and the studied countries regard to cognitive areas?

The content of textbooks contains a set of concepts, principles, skills, values and attitudes which are selected and organized by the planners to achieve the goals; they are in line with the cognitive areas. Their content is theoretical aspect and learning involves mental and intellectual activities. The common aspect of books content in line with the cognitive areas of physics textbooks is discussed in headlines.

Question 7: What is the difference in content of physics textbooks between Iran and the studied countries regard to cognitive areas?

In some countries, the physics syllabus incompletely different to other countries so that in Turkey, the headline of Physics9,10 is same as physics syllabus of our country (T.C, 2007a, pp. 34-35, 2007b, pp. 31-32), but in the sixth chapter (last chapter) of physics 11, 12 in Turkey there is a discussion of astronomy, stars and quasars as (17 hour) with subtitles of stars, classification of stars, heavenly bodies, the stars, the age computation and size of the stars ; the sixth chapter of physics in twelfth grade contains topics as: from atoms to quarks (11 hour) with subtitles of particle and antiparticle, hadrons, Lipton and baryons, mesons, quarks and anti-quarks and in Chapter VII of the issue as the nature of physics (4 hours) with subtitles of hypothesis, the law and the theory has been proposed. These topics are new topics that are not addressed elsewhere in the physics book (T.C, 2007c, pp. 31-32, 2007d, pp. 31-32).

In India, the workshop (practical part) with a total score of 30 points from the total score of physics is considered. And any student performs 10 experiments and 8 activities. In the eleventh grade physics, in fifth chapter, there is a discussion as the system of particles and rigid body (18 sessions) under the subtitles as center of mass of the two-particle system and extension to $\mathrm{N}$ particles, conservation of momentum and move the center of mass, of the same system, rigid body's center of mass, moment of a force, angular momentum, angular momentum, physical concept of angular momentum, conservation of angular momentum, equilibrium of rigid bodies, examples of binary system in nature .In Physics book of twelve degree, in the sixth chapter, some discussions are provided as optics (optics) (26 sessions) with subtitles as refraction, internal failures and its application, blue sky and the appearance of a red sun rising and setting . Chapter 9 discussed about solids and semiconductor devices (20 sessions) with subtitles as energy bands in solids, semiconductor capacitor, diode laser and the Chapter 10 discussed some topics as principles for telecommunications (20 sessions) with subtitles as introductory communications theory, digital and analogue communications, need to modeling, the EM waves in atmosphere, basics of light modeling. These issues are new issues that are not addressed elsewhere in the physics book (The Central Board of Secondary Education, 2011, pp. 71-74).

In Australia, two physics books will be presented in the sixth grade (eleven and twelve) in titles preliminary Physics and advanced Physics which a part of latter contains the preliminary stage. Advanced stage is mixed with the studies of main part and the optional part. The main part of this stage includes:

Space (30 hours, theoretical), motors and generators (30 hours, theoretical), from ideas to application (30 hours theoretical,), the optional part contains 30 hours of theory, including: geo-physics, medical physics, astrophysics, from quantum to quarks (quantum physics), the age of "Silicon" (The Board of studies, 2004, pp. 44-76).

In England, the physics book contain subjects which are not discussed in other countries .For example, in physics 1 book, there is a discussion about the risk possibility of different types of electromagnetic radiation in chapter 5, the comparison of variety of telescopes and observations from them in chapter 11. In UK, Physics 3 book has a discussion of ultrasound in Chapter 8 and the history of the stars in chapter 11 shown the headlines of Physics books in tenth, eleventh and twelve grades in UK (Assement and Qualification Alliance (AQA), 2008, pp. 33-53).

While the number of chapters of school physics textbooks is small but bulky discussions are provided in these chapters in Iran that the teacher has to waste more time to express extra subjects because of inappropriate evaluations of book content.

\section{Discussion}

Physics is a basic science and its importance is obvious for every citizen in each country. So the physics curriculum in secondary education was investigated in terms of adapting to the educational goals. So that if there is some shortcomings in content and organizing the concepts and subjects or teaching procedures or other relevant curriculum elements, the data collection should be done to improve them (Shekarbaghani \& 
Sadroalashrafi, 2012, p. 112).

The common aspect of content selection of physics in Iran and other studied countries is using the program outlines. However, the program outlines determine the teaching type and methods in Iran and decline the role of teacher as a presenter on the program. In the case of the studied countries, the program outlines allow teachers to choose different methods of teaching to meet the needs of students and teachers select the appropriate content of the curriculum in regard to interaction with students and by taking their talents and interests. They implement an appropriate test theoretically and practically to test these education contents. Therefore, there is not similarity in teaching method of studied countries and Iran, Also there is significant different between them in regard to objects, components, backgrounds, approaches and assessment methods as well as selection methods and organization of content which is not discussed in many cases of Physic program in Iran or is not considered as important subject.

In most of the studied countries, the headlines are provided with lower subtitles and less redundancy, while time devoted to teaching these subjects is more than our country's schools. This is because these countries have the sufficient opportunity to manage the classroom in active and student-centered approach, while our physics teachers often complain about lack of time. Results obtained from this study indicate that new training approaches in Iran has not implemented in accordance with curricula in all schools. It seems that in our country, physics teaching must be done through experiments and learning the details of the course material must be assigned to students, to achieve them using test, this can prevent the waste of teacher's time and energy active and student-centered approach in physics teaching will increase creative thinking in students. Physics textbooks must use new materials in accordance to the students' needs in daily life and avoid unnecessary discussions.

In addition, the age of the students and the topics presented in the book must be paid special attention, because in most countries, the physics education is initiated for older students. It is better to express the physics texts with tangible physics examples and less associated with mathematics as much as possible, use the physics examples that students deal with them in daily life and evaluated accordingly. When assessing the academic achievement of students, teachers usually apply traditional valuation (Shekarbaghani, 2006, p. 46). So teachers have not yet reached to sufficient awareness level for implementing these programs and necessary and appropriate steps should be made to educate them further (Ahmadi, 2003, p. 145, Badrian \& Rastegar, 2006, p. 224).

\subsection{Suggestion to Improve the Physics Education in Country}

It is necessary to pay more attention the physics curriculum in Iran's schools to perform the reviews of assessment and examination system of physics, so that provide a simple, up to date and coordinated content by using the tests and the removal of contents entries for the math just done, to use the active teaching method and with emphasis on teaching physics in the physics curriculum. It is recommended to reconsider the revision of the physics books in different grades, holding the teachers' training classes and workshops to train the active teaching methods and training the evaluation techniques in order to learn better student.

\section{References}

Ahmadi, H. (2003). Anthropological principals of evaluation and the necessity to reviews of the existing system. Tehran: The first conference of academic evaluation. Office of Academic and Educational Evaluation.

Assement and Qualification Alliance (AQA). (2008). General Certificate of Secondary Education Physics 4451. Published by AQA Website (www.aqa.org.uk).

Badrian, A., \& Rastegar, T. (2006). A comparative study of education standards of general education courses and successful countries in TIMSS test (report of project plan). the research and educational programs, Tehran. Iran.

Fathi-Vajargah, K. (2002). The principles of curriculum development. Tehran: Iranzamin publishing.

Khalkhali, M. (1996). Reviews of the examination system and assessment of student learning in Iran. Tehran: The Institute of Education.

Maleki, H. (2001). Principals of secondary education curriculum. Tehran: SAMT publishing.

Shabani, H. (2006). Educational Skills (Vol. 1). Tehran: SAMT publishing.

Shekarbaghani, A., \& Sadroalashrafi, M. (2012). Physics Education. Tehran: Madreseh publishing.

Shekarbaghani, A. (2009). Comparative Study of the physics curriculum in Iran and some developed and developing countries (report of project plan). The research and educational programs. Tehran.

Shekrbaghani, A. (2006). Reviews of the evaluation of learning-teaching process and alternative methods. 
Tehran: National Conference on Educational Innovations. Tehran.

T.C. (2007a). Miliegitim Bakanligi, Talim ve Terbiyet Kurulu Baskanligi, Ortaogretim Fizik Dersi9, SINIF, Ogrehim Program. Ankara.

T.C. (2007b). Miliegitim Bakanligi, Talim ve Terbiyet Kurulu Baskanligi, Ortaogretim Fizik Dersi10, SINIF, Ogrehim Program Ankara.

T.C. (2007c). Miliegitim Bakanligi, Talim ve Terbiyet Kurulu Baskanligi, Ortaogretim Fizik Dersi11, SINIF, Ogrehim Program Ankara.

T.C. (2007d). Miliegitim Bakanligi, Talim ve Terbiyet Kurulu Baskanligi, Ortaogretim Fizik Dersi12, SINIF, Ogrehim Program Ankara.

The Board of studies. (2004). Physics stage 6, syllabus. Board bulletin/official notices, 13(3). Published by Board of studies NSW. Sydney. Australia.

The Central Board of Secondary Education. (2011). Physics (Code No. 042). India.

The Ministry of Education Singapore. (2007). Science Syllabus lower Secondary normal (technical). Curriculum planning \& development division. Singapore.

The research and educational programs department. (2001). The Guideline of secondary school physics curriculum. Tehran, Iran.

Turkish Ministry of National Education. (2007). Reviews of National Policies for Education: Basic Education in Turkey. Published by the OECD in 2007

Winston, H. (2007). Basic Education Curriculum Revisited: A Look at the Current Content and Reform. Training and Development Division. Ministry of Education Singapore.

\section{Copyrights}

Copyright for this article is retained by the author(s), with first publication rights granted to the journal.

This is an open-access article distributed under the terms and conditions of the Creative Commons Attribution license (http://creativecommons.org/licenses/by/4.0/). 